\title{
Rocking Aspergillus:
} for the production of secondary metabolites

\author{
Tutku Kurt ${ }^{1}$, Anna-Maria Marbà-Ardébol ${ }^{2}$, Zeynep Turann', Peter Neubauer ${ }^{2}$, Stefan Junne ${ }^{2}$ and Vera Meyer ${ }^{1^{*}}$ (1)
}

\begin{abstract}
Background: Filamentous fungi including Aspergillus niger are cell factories for the production of organic acids, proteins and bioactive compounds. Traditionally, stirred-tank reactors (STRs) are used to cultivate them under highly reproducible conditions ensuring optimum oxygen uptake and high growth rates. However, agitation via mechanical stirring causes high shear forces, thus affecting fungal physiology and macromorphologies. Two-dimensional rockingmotion wave-mixed bioreactor cultivations could offer a viable alternative to fungal cultivations in STRs, as comparable gas mass transfer is generally achievable while deploying lower friction and shear forces. The aim of this study was thus to investigate for the first time the consequences of wave-mixed cultivations on the growth, macromorphology and product formation of A. niger.
\end{abstract}

Results: We investigated the impact of hydrodynamic conditions on A. niger cultivated at a $5 \mathrm{~L}$ scale in a disposable two-dimensional rocking motion bioreactor (CELL-tainer ${ }^{\circledR}$ ) and a BioFlo STR (New Brunswick ${ }^{\circledR}$ ), respectively. Two different A. niger strains were analysed, which produce heterologously the commercial drug enniatin B. Both strains expressed the esyn 1 gene that encodes a non-ribosomal peptide synthetase ESYN under control of the inducible Tet-on system, but differed in their dependence on feeding with the precursors D-2-hydroxyvaleric acid and L-valine. Cultivations of $A$. niger in the CELL-tainer resulted in the formation of large pellets, which were heterogeneous in size (diameter 300-800 $\mu \mathrm{m}$ ) and not observed during STR cultivations. When talcum microparticles were added, it was possible to obtain a reduced pellet size and to control pellet heterogeneity (diameter 50-150 $\mu \mathrm{m}$ ). No foam formation was observed under wave-mixed cultivation conditions, which made the addition of antifoam agents needless. Overall, enniatin B titres of about 1.5-2.3 $\mathrm{g} \mathrm{L}^{-1}$ were achieved in the CELL-tainer ${ }^{\circledR}$ system, which is about $30-50 \%$ of the titres achieved under STR conditions.

Conclusions: This is the first report studying the potential use of single-use wave-mixed reactor systems for the cultivation of A. niger. Although final enniatin yields are not competitive yet with titres achieved under STR conditions, wave-mixed cultivations open up new avenues for the cultivation of shear-sensitive mutant strains as well as high cell-density cultivations.

Keywords: Single-use wave-mixed bioreactor, Aspergillus niger, Cyclodepsipeptide, Enniatin, Heterologous gene expression, Talcum microparticle, Tet-on system, Morphology, Macromorphology

\footnotetext{
*Correspondence: vera.meyer@tu-berlin.de

${ }^{1}$ Department of Applied and Molecular Microbiology, Institute

of Biotechnology, Technische Universität Berlin, Gustav-Meyer-Allee 25,

13355 Berlin, Germany

Full list of author information is available at the end of the article
} 


\section{Background}

Filamentous fungi are of great economic importance as cell factories in industrial biotechnology. Due to their metabolic diversity, high production capacity, secretion efficiency, and the capability of conducting post-translational modifications, filamentous fungi like Aspergillus niger are widely exploited as cell factories for the production of organic acids, proteins and enzymes [1,2]. Of interest is also their natural ability to synthesize bioactive secondary metabolites such as non-ribosomal peptides (NRPs) in large amounts [3, 4]. Due to the dramatic increase in the amount of pathogenic bacteria, which are resistant to commonly used antibiotics, the search for new antibiotics and other pharmaceuticals from fungal resources became one recent focus of the fungal research community [5-7].

An interesting class of bioactive fungal NRPs are the cyclodepsipeptides (CDPs) enniatin, beauvericin, bassianolide and PF1022, all of which consist of alternating units of $N$-methyl amino and $\alpha$-hydroxy acids. CDPs exhibit antibacterial, antifungal, insecticidal, anthelmintic or even anticancer activities. Two of these compounds are commercialized drugs: fusafungine (a mixture of enniatins) is applied as antibacterial compound for treating throat infections in humans and emodepside (a semisynthetic derivative of PF1022A) used as anthelmintic compound in the veterinary medicine [8]. We showed recently that heterologous expression of the NRPS encoding gene esyn1 from Fusarium oxysporum in $A$. niger results in enniatin $\mathrm{B}$ production in multigram scale per litre during a fed-batch cultivation [9]. A prerequisite to achieve such titres is controlled expression of the ESYN encoding gene esyn 1 under the Tet-on system [10] and feeding of the strain with the enniatin B precursors D-2-hydroxyvaleric acid (D-Hiv) and L-valine during cultivation. We also showed that this esyn1 expressing strain DS3.1 became independent from D-Hiv feeding after introduction of the kivR gene from $F$. oxysporum into its genome (resulting in strain ÖV4.10). Constitutive expression of multiple copies of the kivR gene made ÖV4.10 competent to use its intracellular $\alpha$-ketovaleric acid pool for D-Hiv generation. A direct comparison of both strains in $20 \mathrm{~mL}$ shake flask cultures revealed that the enniatin B titres achieved with strain ÖV4.10 are about $75 \%$ of the enniatin B titres of strain DS3.1 [9]. Polycistronic expression of both esyn 1 and kivR under control of the Tet-on expression system resulted in $40 \%$ of the product titres that were achieved with the strain DS3.1 in shake flask cultures. This finding proved that polycistronic secondary metabolite biosynthesis is possible in $A$. niger and suggested that the KivR enzyme catalyses the rate-limiting step in enniatin $B$ biosynthesis [11]. It was furthermore demonstrated that $A$. niger is (i) a superior expression host not only for enniatin B, but also for beauvericin and bassianolide, by producing the highest titres ever reported for heterologous hosts as well as for natural producing organisms [12]; and (ii) an ideal platform strain for the production of new-to-nature CDPs obtained by designing and expressing hybrid CDP synthetases in $A$. niger $[13,14]$. Indeed, some of the novel CDPs displayed considerably higher bioactivities compared to their parental CDPs and reference drugs [14]. The genetic (i.e. synthetic biology) tools to reprogram $A$. niger to overproduce bioactive non-ribosomal peptides at highest level have thus been successfully established and can be applied further to efficiently screen novel secondary metabolites from any fungal resource for desired bioactivities via heterologous expression of their encoding gene clusters in A. niger.

Apart from the necessity to discover and express novel bioactive compounds, another important technological development for their (industrial) production is the application of single-use bioreactors. These offer many opportunities for filamentous fungi as cell factories in pharmaceutical and cosmetics industries as recently highlighted in a White Paper of the EUROFUNG consortium [5]. Single-use bioreactors provide a platform technology, "which is safer (decreased risk of microbial contamination and cross-contamination), greener (reduced requirements for sterilization and cleaning), faster and more flexible (easy process and product changes), and cheaper (saving of time and costs)" [5]. In general, single-use bioreactors are reactor platforms that comprise of a non-disposable part of controllers, motor and housing, and a disposable bag, in which the cultivation is conducted. Several designs of single-use bioreactors were commercialized during the last decade. An increased process flexibility, high turnover and lower risk of cross contaminations led eventually to the penetration of this technology into the pharmaceutical industry [15, 16]. Several reactor types have been described and were compared with conventional non-disposable stirred tank bioreactors based on engineering parameters and process performances [17-22]. Single-use wave-mixed bioreactors are nowadays of interest for the cultivation of shearsensitive cells, such as mammalian cell lines, insect cell lines [23], phototrophic algae [24] and plant hairy roots [25]. Also, successful cultivations with wave-induced agitation have been reported for the filamentous basidiomycetes Flammmulina velutipes and Pleurotus sapidus [26] as recently reviewed in [27].

So far, no reports on submerged cultivations of $A$. niger in single-use wave-mixed bioreactor systems have been published. A. niger and in general filamentous fungi adopt different microscopic and macroscopic morphological forms during submerged cultivations, the latter varying 
from a freely dispersed mycelium over loose mycelial clumps to dense pellets [28, 29]. Whereas dispersed mycelia increase medium viscosity and are sensitive to shear stress, oxygen and nutrient transfer is impaired in the core of pellets [30-32]. Process parameters, which affect the development of different macromorphologies range from inoculum concentration [33] and medium composition [31, 34] over reactor shape, stirrer geometry and stirrer speed (generating different shear forces) [35], aeration rate [36] to $\mathrm{pH}$ and temperature [37]. It was shown that macroscopic morphologies affect protein secretion rates in aspergilli in many, but not all cases [36, 38-47]. Unfortunately, the adequate macroscopic fungal morphology for given target products including organic acids, secreted proteins or secondary metabolites varies, cannot be generalized, and the advantages and disadvantages of mycelial or pellet cultivation have to be carefully adjusted for a given process and the final production scale [32, 35, 41, 48-57].

The main objective of this study was thus to determine whether a two-dimensional (horizontal and vertical) rocking-motion wave-mixed bioreactor is a viable alternative to well-established conventional STRs for the cultivation of $A$. niger. We therefore systematically analyzed for the first time the impact of controlled low shear stress cultivation on the growth of $A$. niger, the evolution of its macroscopic morphology and its product formation by cultivating the fungus in the wave-mixed bioreactor CELL-tainer. The two enniatin B-expressing strains DS3.1 and ÖV4.10 described above were used for this survey. They were cultivated under nutrient-limited fedbatch cultivation conditions with identical medium compositions, feeding schemes, temperature and $\mathrm{pH}$ control as described in our previously published STR cultivations [9] to allow a direct comparison. Naturally, we induced synthesis of enniatin $B$ as model product via induction of the Tet-on expression system using the inductor doxycycline as previously described for STR cultivations [9].

\section{Results}

The development of fungal macroscopic morphologies during submerged cultivations is a multifactorial process. Therefore, the final macromorphologies are unpredictable. However, from our experiences with STR cultivations of A. niger using BioFlo3000 reactors (5 L working volume, New Brunswick Scientific, NJ), we know that the chosen medium composition (see "Methods" section), a constant $\mathrm{pH}$ value of 3 and a stirrer speed of $750 \mathrm{rpm}$ altogether ensure the formation of dispersed mycelia (Fig. 1A, panel a). Under these conditions, the formation of loose clumps or small pellets is a rare event (about 10-15\%, Fig. 1A, panels b, c; $[57,58]$ ). This is also observed for the enniatin B producing strain DS3.1 [9].
Note that shear forces in the CELL-tainer were lower at exactly the same operation conditions as applied in this study when compared to STR cultivations of the heterotrophic algae Cryptecodinium cohnii, which thus provoked less or even no cell lysis during operation [59, 60]. As the CELL-tainer system thus likely exhibits also less shear forces on $A$. niger, we first wished to analyse the macromorphologies from duplicate cultures of strain DS3.1, which followed exactly the same nutrient-limited fed-batch cultivation scheme as previously reported for the same strain in the BioFlo3000 reactor system [9]. Applying similar parameters under wave-mixed motion, however, lead to strong pellet formation of DS3.1 (Fig. 1A, panels b, d), which accounted for about $90 \%$ of macromorphological units $(n>100)$. The pellet population was highly diverse in shape (round-oval) and size (diameter between 300 and $800 \mu \mathrm{m}$ ). We thus measured both width and length of $\sim 100$ macromorphological units in STR and wave-mixed cultivations. Pellet sizes varied between 300 and $700 \mu \mathrm{m}$ width, 500 and $800 \mu \mathrm{m}$ length, which resulted in a projected area of $0.5-1.5 \mathrm{~mm}^{2}$ in wave-mixed cultivations (Fig. 1B-D). Note that some pellets displayed a highly condensed form, while some were surrounded by many loose filaments (Fig. 1A, panel b). Therefore, only the condensed part of each pellet was considered for the calculation of the pellet size.

Addition of talcum microparticles consisting of hydrous magnesium silicate to cultivation media was reported as a successful strategy to reduce pellet sizes of A. niger [32, 43]. The addition of $10 \mathrm{~g} \mathrm{~L}^{-1}$ talcum positively affected enniatin B production of strain DS3.1 in shake flask cultivations [9]. The addition of $10 \mathrm{~g} \mathrm{~L}^{-1}$ talcum to wave-mixed cultivations of the strains DS3.1 and ÖV4.10 decreased indeed pellet formation and led to macroscopic morphologies similar to STR cultivations (Fig. 1B-D and Table 1). The percentage of pelletforming units decreased from $90 \%$ without talcum to $15 \%$ with talcum and the sizes of the macromorphological units were considerably reduced to values between 50 and $100 \mu \mathrm{m}$ (width), 50 and $150 \mu \mathrm{m}$ (length) and to values $\leq 0.1 \mathrm{~mm}^{2}$ (projected area).

Notably, the addition of talcum to DS3.1 and ÖV4.10 wave-mixed cultivations led also to reproducible growth curves, which was not the case for wave-mixed cultivations of DS3.1 without the addition of talcum (Fig. 2a). In the latter, high variations in physiological parameters (glucose and oxygen consumption, carbon dioxide production, biomass accumulation) and (by-)product formation (enniatin B, pyruvate, lactate) were observed (Figs. 2b, d, 3). This was likely a consequence of the high morphological variability of DS3.1 growth units. The respiratory quotient $\mathrm{RQ}$, which is the ratio of the volumetric carbon dioxide production rate $\mathrm{Q}_{\mathrm{CO}_{2}}$ to the volumetric 

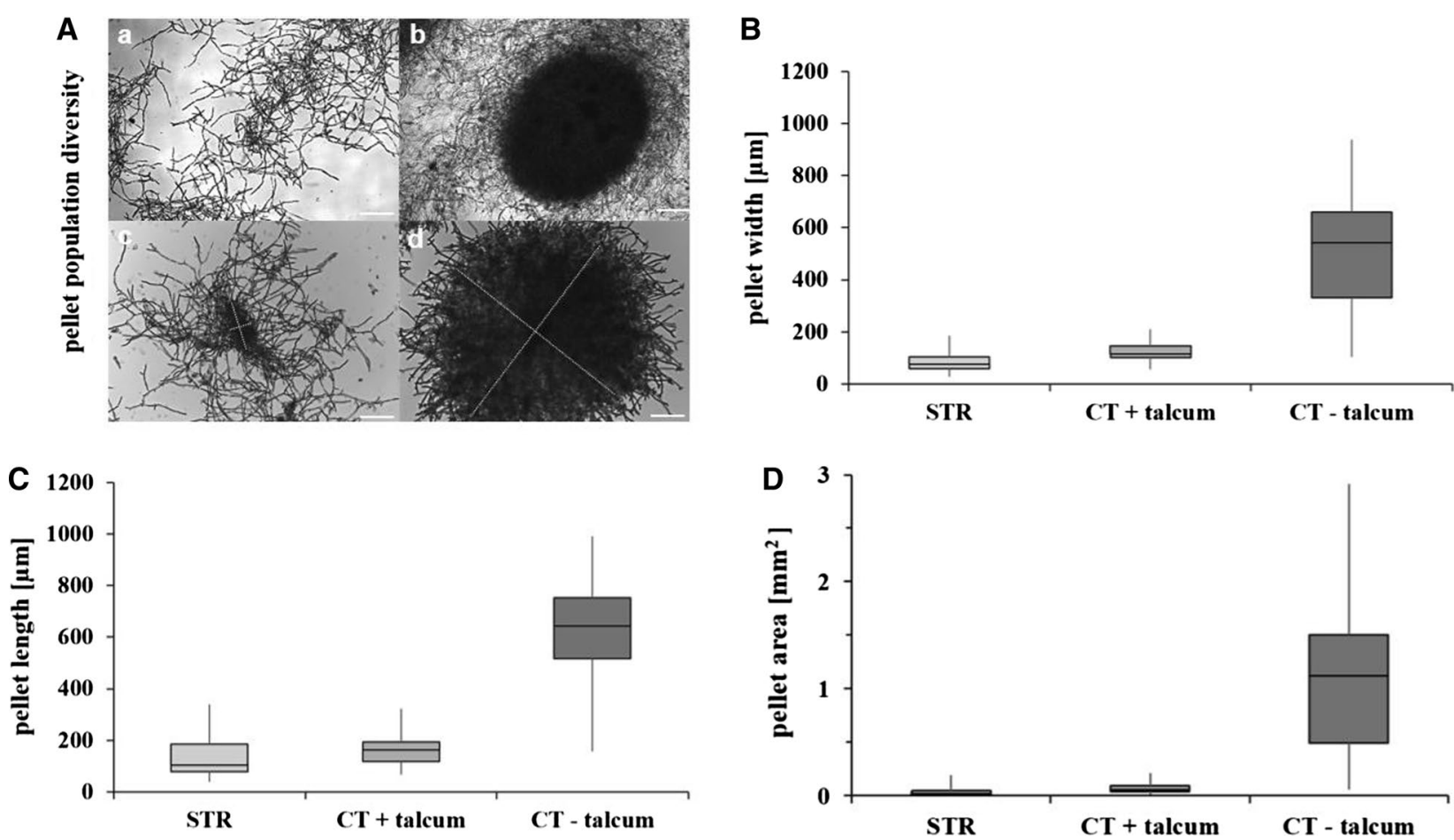

Fig. 1 Macromorphological units observed during submerged fed-batch cultivations of A. niger. A Diversity of macromorphologies observed during STR (a) and CELL-tainer cultivations (b-d). Note that pellet formation could be prevented by addition of talcum microparticles to the medium (c). Only condensed regions of the pellets were considered for determination of their width and length (c, d). Scale bar: $100 \mu \mathrm{m}$. The pellet size was calculated by measuring the width (B) and the length (C) of more than 100 macromorphological units per cultivation run and calculating the area (D) with the formula $A=\pi$ width length

Table 1 Growth and morphological parameters obtained from A. niger during submerged fed-batch cultivations

\begin{tabular}{|c|c|c|c|c|c|c|}
\hline Strain A. niger & Reactor system & Cultivation mode & Pellet formation & $\begin{array}{l}\text { Specific growth } \\
\text { rate } \mu_{\max }\left(h^{-1}\right)\end{array}$ & $\begin{array}{l}\mathrm{C}_{\text {biomass,max }} \\
\left(\mathrm{g}_{\text {dryweight }} \mathrm{kg}^{-1}\right)\end{array}$ & Reference \\
\hline DS3.1 & BioFlo3000 & Fed-batch & $+(\sim 15 \%)$ & 0.15 & 24.9 & [9] \\
\hline DS3.1 & CELL-tainer ${ }^{\circledR}$ & Fed-batch & $+++(\sim 90 \%)$ & 0.24 & 31.6 & This study \\
\hline DS3.1 & CELL-tainer ${ }^{\circledR}$ & Fed-batch & $+++(\sim 90 \%)$ & 0.24 & 29.8 & This study \\
\hline DS3.1 & CELL-tainer ${ }^{\circledR}$ & Fed-batch + talcum & $+(\sim 15 \%)$ & 0.11 & 34.0 & This study \\
\hline DS3.1 & CELL-tainer ${ }^{\circledR}$ & Fed-batch + talcum & $+(\sim 15 \%)$ & 0.12 & 35.7 & This study \\
\hline ÖV4.10 & CELL-tainer ${ }^{\circledR}$ & Fed-batch + talcum & $+(\sim 15 \%)$ & 0.11 & 27.7 & This study \\
\hline ÖV4.10 & CELL-tainer ${ }^{\circledR}$ & Fed-batch + talcum & $+(\sim 15 \%)$ & 0.11 & 27.9 & This study \\
\hline
\end{tabular}

oxygen uptake rate $\mathrm{Q}_{\mathrm{O}_{2}}$, differed considerably between the wave-mixed cultivations if talcum was added or not. The RQ value is a good indirect measure for the physiological state of a culture and independent of its cell number. During growth on carbohydrates, an RQ value of 1 is an indicator for balanced aerobic metabolism, whereas an RQ value differing from 1 suggests metabolic discrepancies or even metabolic stress. DS3.1 cultivations, if supplemented with talcum, achieved a constant RQ of 1 throughout the whole cultivation time ( $200 \mathrm{~h}$, Fig. 3). If cultivated in absence of talcum, however, the RQ value varied between 0.3 and 1.6 within the first $10 \mathrm{~h}$ of cultivation before it reached a constant value of 1 until $180 \mathrm{~h}$. During the last $20 \mathrm{~h}$, it increased to a value of 2 due to a slightly faster decreasing $\mathrm{Q}_{\mathrm{O}_{2}}$ (Fig. 3). Most interestingly, DS3.1 cultivated under wave-mixed conditions reached higher maximal specific growth rates $\left(0.24 \mathrm{~h}^{-1}\right)$ in the absence of talcum when compared to its cultivation in the presence of talcum $\left(0.11 \mathrm{~h}^{-1}\right)$, but lower final biomass titres $\left(\sim 30 \mathrm{~g} \mathrm{~kg}^{-1}\right.$ compared to $\sim 35 \mathrm{~g} \mathrm{~kg}^{-1}$; Fig. 2a and Table 1). Faster growth of DS3.1 in the absence of talcum became also evident when the concentration of glucose 

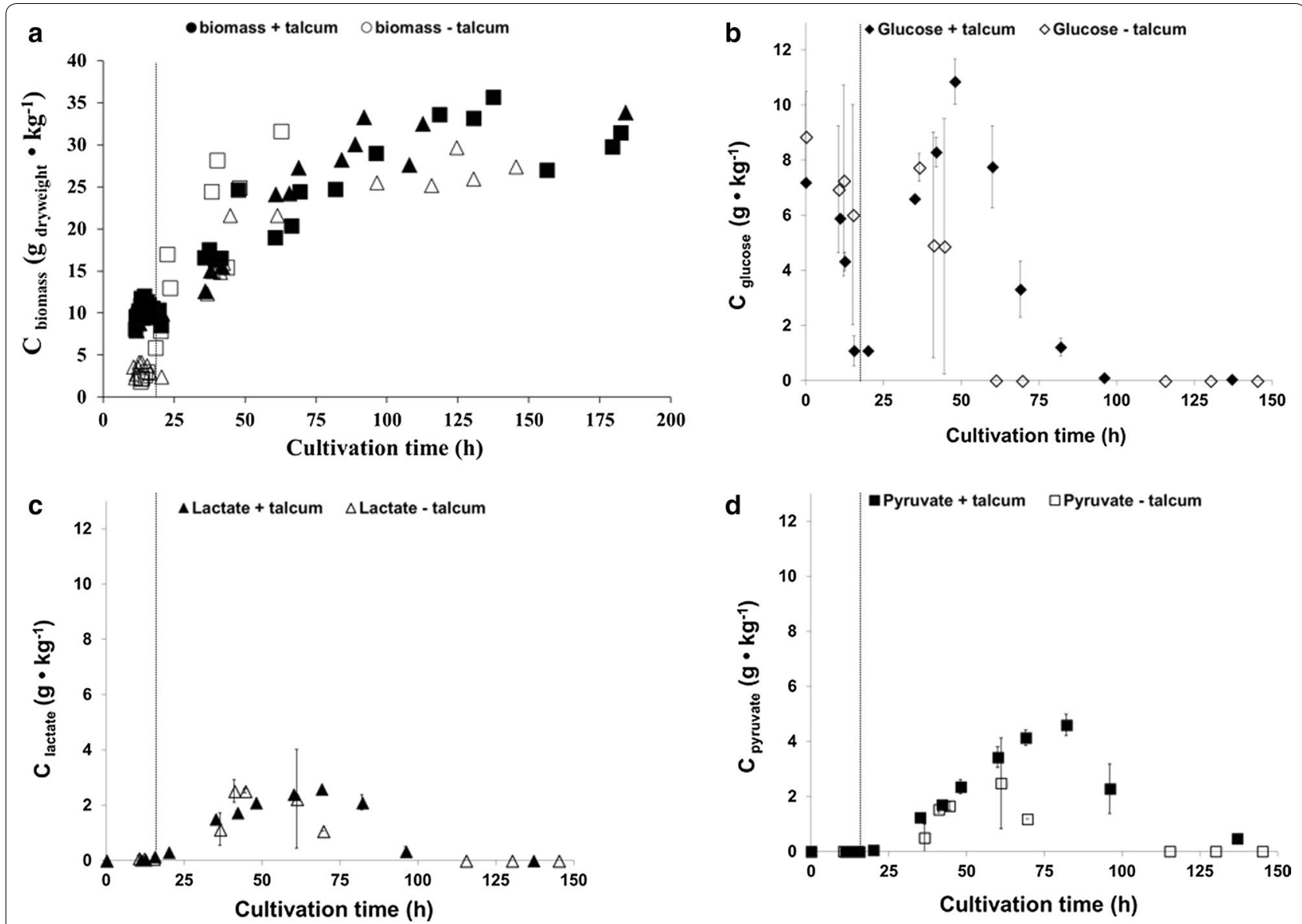

Fig. 2 Growth and physiological profiles of duplicate A. niger cultures (strain DS3.1) during wave-mixed fed-batch cultivations. a Biomass titers produced by DS3.1 with talcum addition (closed symbols, replicates are represented by closed triangles and closed squares) and without talcum addition (open symbols, replicates are represented by open triangles and open squares). b Glucose concentrations in cultivations with (closed symbols) and without (open symbols) talcum. c Lactate concentrations in cultivations with (closed symbols) and without (open symbols) talcum. d Pyruvate concentrations in cultivations with (closed symbols) and without (open symbols) talcum. Start of glucose-feed and time of induction of Tet-on driven esyn expression via doxyxycline addition is indicated with a dashed line

and the by-product lactate were measured in culture samples at different time points. As depicted in Fig. 2c and $\mathrm{d}$, glucose and lactate depleted already after $\sim 60 \mathrm{~h}$ in the DS3.1 cultivations without talcum addition, but only after $\sim 90 \mathrm{~h}$ in the cultivations with $10 \mathrm{~g} \mathrm{~L}^{-1}$ talcum. Since the same amount of nutrients were available in both cases, a lower concentration of biomass and lactate has to result in the accumulation of other by-products, which are not re-assimilated for growth or main product formation at the later stage of the cultivation. Altogether, these observations suggest that morphology engineering via talcum addition decreases and homogenises pellet sizes. This however, leads to a lower specific growth rate and slower byproduct accumulation.

Enniatin B titres measured in DS3.1 and ÖV4.10 biomass samples harvested in the CELL-tainer system in the presence or absence of talcum after $100 \mathrm{~h}$ of fed-batch cultivation are depicted in Fig. 4. We decided to display the data in a box-whisker plot graphic as enniatin B values usually sway a lot in biological and technical duplicates. As expected, DS3.1 surpasses strain ÖV4.10 regarding enniatin B production in compliance with our previous findings in shake flask cultivations [9]. The data also demonstrate that volumetric as well as specific enniatin B yields are higher in DS3.1 cultures when cultivated in the presence of talcum ( $\left.2.5 \mathrm{~g} \mathrm{~kg}^{-1} / 0.08 \mathrm{~g} \mathrm{~g}^{-1} \mathrm{DW}\right)$ compared to cultivations in the absence of talcum $\left(1.4 \mathrm{~g} \mathrm{~kg}^{-1} / 0.055 \mathrm{~g} \mathrm{~g}^{-1} \mathrm{DW}\right)$, indicating that smaller pellet sizes and slower growth are advantageous for enniatin B production. However, the enniatin B yields of DS3.1 in wave-mixed cultivations are lower compared to the yield obtained in the STR $\left(0.18 \mathrm{~g} \mathrm{~g}^{-1} \mathrm{DW}\right)[9]$. 


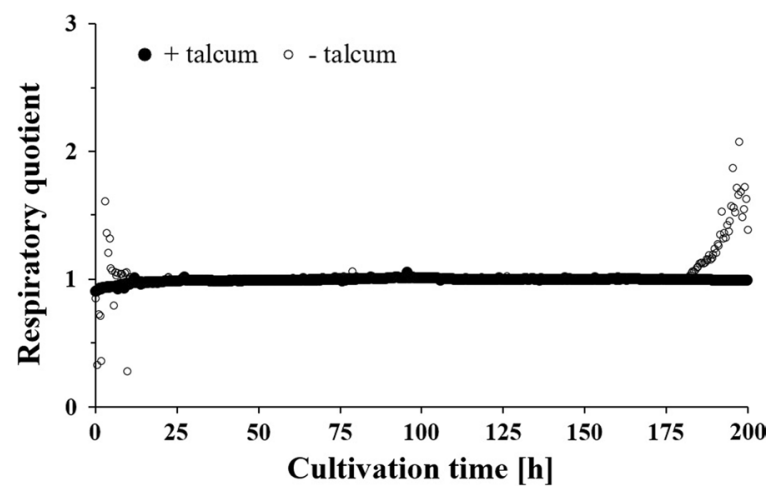

Fig. 3 Evolution of the respiratory quotient during wave-mixed fed-batch cultivations of $A$. niger strain DS3.1. Cultivations supplemented with talcum (closed symbols) achieved a constant RQ of 1 throughout cultivation. In absence of talcum (open symbols), the $R Q$ value varied between 0.3 and 1.6 within the first $10 \mathrm{~h}$ of cultivation and during the last $20 \mathrm{~h}$ of cultivation

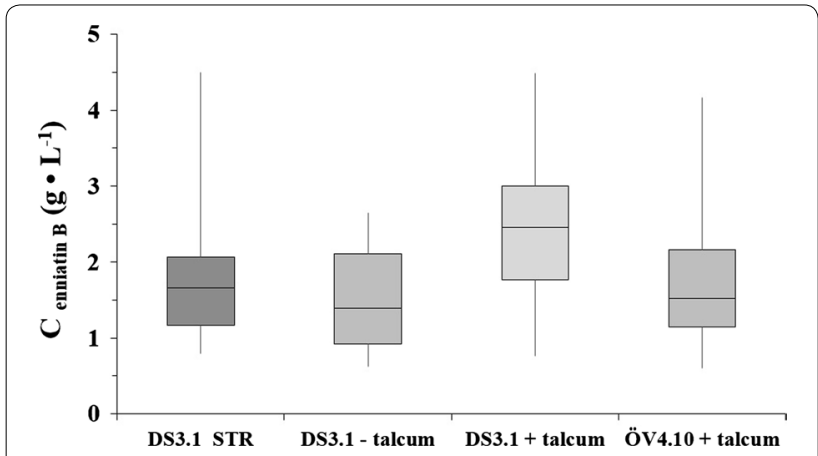

Fig. 4 Enniatin $B$ titres during wave-mixed fed-batch cultivations obtained from the A. niger strains DS3.1 and ÖV4.10. Volumetric enniatin B yields ( $\mathrm{g} \mathrm{L}^{-1}$ culture broth) from duplicate cultures are given, which were measured as technical replicates. Enniatin B was determined after $100 \mathrm{~h}$ of each cultivation approximately every $10 \mathrm{~h}$. Biological and technical replicates are summarized in each boxwhisker-plot

\section{Discussion}

Increased process flexibility, high turnover and lower risk of cross-contaminations in single-use bioreactor systems underpin the importance of this technology for the pharmaceutical industry $[15,16]$. Another advantage is the design flexibility that made different geometries available. The aim of this study was to investigate the impact of low shear forces generated in the singleuse wave-mixed CELL-tainer on growth, development of macroscopic morphologies and enniatin $B$ product formation in $A$. niger and to compare the data with physiological and morphological data obtained for $A$. niger STR cultivations in a BioFlo3000 STR.

A critical parameter for any process design for aerobic cultivations is the volumetric oxygen transfer coefficient $k_{L}$ a of the reactor. The $k_{L} a$ value describes the capacity of a given system to introduce oxygen into the liquid phase. To increase the $\mathrm{k}_{\mathrm{L}} \mathrm{a}$, vigorous stirring or shaking is necessary to break up air bubbles, thereby increasing the area of the liquid-gas interface. Stirring is the main reason for the high shear stress in STRs. While one-dimensional rocking reactors exhibit relatively low $\mathrm{k}_{\mathrm{L}}$ a values of 1 to $5 \mathrm{~h}^{-1}, \mathrm{k}_{\mathrm{L}} \mathrm{a}$-values beyond $400 \mathrm{~h}^{-1}$ were reported for wave-mixed bioreactors [17, 27], similar to values obtained in lab-scale stirred tank reactors with stirring rates as applied in this study. The CELL-tainer concept was thus successfully applied for aerobic fed-batch cultivations of Escherichia coli, in which typical growth rates and recombinant protein expression levels were achieved [17]. Notably, specific growth rates for $A$. niger cultivated under identical nutrient-limited fed-batch cultivations under wavemixed conditions are considerably higher $\left(0.24 \mathrm{~h}^{-1}\right)$ in comparison to STR cultivations $\left(0.15 \mathrm{~h}^{-1}\right)$, indicating that high shear forces under stirred agitations indeed limit the growth of $A$. niger. It is conceivable that reduced shear stress under wave-mixed conditions allows self-assembly of $A$. niger growth units, which generate the natural architecture for a very heterogeneous pellet population, which is eventually important to ensure fast nutrient uptake, and thus biomass accumulation. This data also suggests that macromorphological pellet heterogeneity of $A$. niger can be beneficial to the growing population to grow as fast as possible. This hypothesis is highly speculative and has not been studied yet in filamentous fungi; however, many studies, which investigated bacterial population heterogeneities indeed propose that even single cells follow a population-based strategy to allocate different tasks to different cells (e.g. to specialise on different metabolic pathways) in order to maximise population growth [61-63]. Given that macromorphological pellet heterogeneity provides a fitness advantage to $A$. niger, one would expect that this advantage will get lost when the pellet size becomes homogeneous. This is exactly what we have observed after the addition of talcum to wave-mixed cultures: the specific growth rate dropped to $0.11 \mathrm{~h}^{-1}$ and glucose was metabolised much slower (Figs. 1, 2 and Table 1). On the one hand, talcum microparticles could probably interfere with important physical factors that control the self-organisation of growth units, especially in early growth phases (note that RQ variations during the first $10 \mathrm{~h}$ were only evident for wave-mixed cultivations lacking talcum; Fig. 3), on the 
other hand, talcum microparticles might cause additional friction stress to $A$. niger. We are currently studying this hypothesis further on the molecular level.

In conclusion, CELL-tainer cultivations seem to be superior for fast biomass accumulation of $A$. niger and could thus be interesting for growth-coupled product formation such as primary metabolites (organic acids) or even secreted proteins. The synthesis of enniatin $\mathrm{B}$, however, is linked to secondary metabolism of $A$. niger. We showed previously that reduced growth rates and even carbon starvation are beneficial for higher enniatin $B$ yields, likely because it generally activates secondary metabolism of $A$. niger $[9,58,64]$. Hence, one would expect lower enniatin $B$ yield in fast-growing cultures like in wave-mixed cultivations of DS3.1 lacking talcum compared with slow-growing wave-mixed cultures of DS3.1 with talcum. This is indeed what we have observed in this study (Fig. 4).

\section{Conclusions}

In this study, we present a single-use wave-mixed bioreactor concept as an alternative to well-established conventional STR cultivations for $A$. niger for the first time. The CELL-tainer system can ensure higher specific growth rates than in the STR cultivations and, interestingly, does not require the addition of antifoam agents as no foam formation was observed (data not shown). It thus makes the addition of antifoaming agents needless, as previously reported for wave-mixed bioreactor systems [18]. We thus conclude that this reactor system has a very high potential for growth-coupled production processes for $A$. niger, in which the formation of macromorphologies should remain unrestricted. For secondary metabolite production, however, wavemixed cultivation needs to be further optimized with respect to controllable pellet morphologies.

\section{Methods}

Strains and media

Aspergillus strains used in this study are summarized in Table 2 and were previously described [9]. Spores of $A$. niger strains were obtained and harvested as

Table 2 A. niger strains used in this study

\begin{tabular}{|c|c|c|}
\hline Strain & Relevant genotype & References \\
\hline DS3.1 & Tet-On-esyn 1-T trpa, $p y r G^{+}$, single copy & [9] \\
\hline ÖV4.10 & $\begin{array}{l}\text { Tet-On-esyn1-T }{ }_{\text {trpc }} \text { pyrG }{ }^{+} \text {, single copy; } \\
P_{\text {gpdA }} \text {-ekivR-T trpc } \text {-amdS }^{-a m}\end{array}$ & [9] \\
\hline
\end{tabular}

described in Refs. $[9,11]$ and used freshly to inoculate bioreactors.

\section{Bioreactor cultivation}

Submerged cultivations were performed with $6.6 \mathrm{~L}$ BioFlo3000 bioreactors (New Brunswick Scientific, NJ, USA) and in the $20 \mathrm{~L}$ disposable wave-mixed bioreactor CELLtainer ${ }^{\circledR}$. The main fermentation settings were already described in Refs. [9, 58, 64]. In brief, fed-batch cultivations were inoculated with spore suspension of $A$. niger strains with a spore titre of $10^{9}$ conidia $\mathrm{L}^{-1}$ and $0.003 \%$ yeast extract to improve germination. Initial batch cultivations were conducted with $4 \mathrm{~L}$ of cultivation medium, containing $0.8 \%$ glucose $\left(\mathrm{w} \mathrm{v}^{-1}\right)$. When reaching the late exponential growth phase, the Tet-on system was induced by addition of $20 \mu \mathrm{g} \mathrm{mL}^{-1}$ doxycycline (Dox). At the same time, the feed was started with a feeding rate of $\mathrm{F}=0.046 \mathrm{~L} \mathrm{~h}^{-1}$. The feed medium $(1.5 \mathrm{~L})$ contained $5 \%$ glucose, $0.5 \%$ yeast extract, $0.1 \%$ casamino acids, $20 \mathrm{mM}$ D-2-hydoxyvaleric acid (D-Hiv) and $20 \mathrm{mM}$ L-valine for DS3.1 and $40 \mathrm{mM} \mathrm{L-valine} \mathrm{for} \mathrm{ÖV4.10} \mathrm{cultiva-}$ tions additionally to the initial fermentation medium. In total, $100 \mu \mathrm{g} \mathrm{mL}^{-1}$ of Dox were added to the culture (20 $\mu \mathrm{g} \mathrm{mL}^{-1}$ of Dox addition every 4-7 h). A temperature of $30{ }^{\circ} \mathrm{C}$ was kept constant throughout the whole cultivation process and a $\mathrm{pH}$-value of 3.0 was maintained by addition of $2 \mathrm{M} \mathrm{NaOH}$ or $1 \mathrm{M} \mathrm{HCl}$, respectively. The aeration rate was kept constant at $1 \mathrm{~L} \mathrm{~min}^{-1}$.

The rocking motion of the CELL-tainer was initially set to $5 \mathrm{rpm}$ during the germination phase of $5-6 \mathrm{~h}$. The rocking speed was controlled between 15 and $45 \mathrm{rpm}$ after germination, depending on the dissolved oxygen (DO) value output (DO-controlled rpm mode).

\section{Metabolite and gas analysis}

Metabolite analysis of the supernatant samples (i.e. carbohydrates and short chain carboxylic acids) was conducted with a refractometric detector on HPLC systems as previously described [65]. Enniatin extraction and measurements were performed as previously described [9]. In brief, defined amounts of biomass were subjected to ethyl acetate extraction, centrifuged and evaporated. Samples were dissolved in $40 \%$ isopropanol, diluted 10 to 10,000 -fold and enniatin concentration quantified by ESI-Triple-Quadrupol-MS (6460 Series, Agilent Technologies) analysis in the multiple reaction monitoring mode [9]. Enniatin isolated from $F$. oxysporum was used as an external standard to generate a calibration curve out of the manually integrated peak areas for each measurement. The $\mathrm{O}_{2}$ and $\mathrm{CO}_{2}$ content in the off-gas was measured with the Blue-In-One analyser (Bluesens). 


\section{Microscopy and determination of pellet size}

Mycelia and pellets were stained with lactophenol blue and analysed with differential interference contrast (DIC) microscopy using Leica DM 5000 CS and evaluated using Leica's microscope software LAS V4.3. Image analysis of the pellet width and length was performed using ImageJ 1.51p. Disperse mycelia, loose clumps or dense pellets were each defined as macromorphological unit given that they were individually distinguishable by microscopy from each other. More than hundred macromorphological units were analysed per sample.

\section{Equations}

The specific growth rate $\mu$ was determined by plotting the logarithm of the biomass against the cultivation time during exponential growth. Respiratory quotient $(\mathrm{RQ})$, volumetric oxygen uptake rate $\left(\mathrm{Q}_{\mathrm{O}_{2}}\right)$ and volumetric carbon dioxide production rate $\left(\mathrm{Q}_{\mathrm{CO}_{2}}\right)$ were calculated following Eqs. (1), (2), (3).

$$
\begin{aligned}
& Q_{O_{2}}=\frac{\dot{V}_{G}^{\alpha}}{V_{F} \cdot 22.4}\left[Y_{O_{2}}^{\alpha}-\frac{1-Y_{O_{2}}^{\alpha}-Y_{O_{2}}^{\alpha}}{1-Y_{O_{2}}^{\omega}-Y_{C_{2}}^{\omega}} \cdot Y_{O_{2}}^{\omega}\right] \\
& Q_{C O_{2}}=\frac{\dot{V}_{G}^{\alpha}}{V_{F} \cdot 22.4}\left[Y_{C O_{2}}^{\omega} \cdot \frac{1-Y_{O_{2}}^{\alpha}-Y_{O_{2}}^{\alpha}}{1-Y_{O_{2}}^{\omega}-Y_{C O_{2}}^{\omega}}-Y_{\mathrm{CO}_{2}}^{\alpha}\right] \\
& R Q=\frac{Q_{C O_{2}}}{Q_{O_{2}}}
\end{aligned}
$$

\section{Data fitting}

Off-gas data were fitted with the fitting toolbox of SigmaPlot TableCurve 2D v5.01 (Systat Software Inc.).

\section{Authors' contributions}

VM and SJ conceived of the study. TK, AMMA, ZT conducted experiments. TK, VM and SJ analysed and interpreted data and generated figures. TK, SJ and VM wrote the manuscript. PN contributed with discussions. All authors read and approved the final manuscript.

\section{Author details}

1 Department of Applied and Molecular Microbiology, Institute of Biotechnology, Technische Universität Berlin, Gustav-Meyer-Allee 25, 13355 Berlin, Germany. ${ }^{2}$ Chair of Bioprocess Engineering, Institute of Biotechnology, Technische Universität Berlin, Gustav-Meyer-Allee 25, 13355 Berlin, Germany.

\section{Acknowledgements}

The authors wish to thank Simon Boecker and Prof. Roderich Süssmuth (TU Berlin) for support with enniatin B measurements.

\section{Competing interests}

The authors declare that they have no competing interests.

\section{Availability of data and materials}

Data and materials generated during and/or analysed in the current study are available from the corresponding author on request.

\section{Consent for publication}

Not applicable.

Ethics approval and consent to participate

Not applicable.

\section{Publisher's Note}

Springer Nature remains neutral with regard to jurisdictional claims in published maps and institutional affiliations.

Received: 12 June 2018 Accepted: 9 August 2018

Published online: 21 August 2018

References

1. Meyer V, Wu B, Ram AFJ. Aspergillus as a multi-purpose cell factory: current status and perspectives. Biotechnol Lett. 2011;33:469-76.

2. Cairns TC, Nai C, Meyer V. How a fungus shapes biotechnology: 100 years of Aspergillus niger research. Fungal Biol Biotechnol. 2018;5:13.

3. Meyer V. Genetic engineering of filamentous fungi-progress, obstacles and future trends. Biotechnol Adv. 2008;26:177-85.

4. Lubertozzi D, Keasling JD. Developing Aspergillus as a host for heterologous expression. Biotechnol Adv. 2009;27:53-75.

5. Meyer V, Andersen MR, Brakhage AA, Braus GH, Caddick MX, Cairns TC, et al. Current challenges of research on filamentous fungi in relation to human welfare and a sustainable bio-economy: a white paper. Fungal Biol Biotechnol. 2016;3:6.

6. Nielsen JC, Grijseels S, Prigent S, Ji B, Dainat J, Nielsen KF, et al. Global analysis of biosynthetic gene clusters reveals vast potential of secondary metabolite production in Penicillium species. Nat Microbiol. 2017:2:17044

7. Weinhold M, Mast-Gerlach E, Meyer V. Vita activa in biotechnology: what we do with fungi and what fungi do with us. Fungal Biol Biotechnol. 2017:4:14.

8. Dang T, Süssmuth RD. Bioactive peptide natural products as lead structures for medicinal use. Acc Chem Res. 2017;50:1566-76.

9. Richter L, Wanka F, Boecker S, Storm D, Kurt T, Vural Ö, et al. Engineering of Aspergillus niger for the production of secondary metabolites. Fungal Biol Biotechnol. 2014;1:4.

10. Meyer V, Wanka F, Van Gent J, Arentshorst M, Den Van, Hondel CAMJJ, Ram AFJ. Fungal gene expression on demand: an inducible, tunable, and metabolism-independent expression system for Aspergillus niger. Appl Environ Microbiol. 2011;77:2975-83.

11. Schuetze T, Meyer V. Polycistronic gene expression in Aspergillus niger. Microb Cell Fact. 2017;16:162.

12. Boecker S, Grätz S, Kerwat D, Adam L, Schirmer D, Richter L, et al. Aspergillus niger is a superior expression host for the production of bioactive fungal cyclodepsipeptides. Fungal Biol Biotechnol. 2018;5:4.

13. Zobel S, Boecker S, Kulke D, Heimbach D, Meyer V, Süssmuth RD. Reprogramming the biosynthesis of cyclodepsipeptide synthetases to obtain new enniatins and beauvericins. ChemBioChem. 2016;17:283-7.

14. Steiniger C, Hoffmann S, Mainz A, Kaiser M, Voigt K, Meyer V, et al. Harnessing fungal nonribosomal cyclodepsipeptide synthetases for mechanistic insights and tailored engineering. Chem Sci. 2017;8:7834-43.

15. Langer ES. Single-use bioreactors get nod. Genet Eng Biotechnol News. 2012;32:16

16. Jacquemart R, Vandersluis M, Zhao M, Sukhija K, Sidhu N, Stout J. A singleuse strategy to enable manufacturing of affordable biologics. Comput Struct Biotechnol J. 2016;14:309-18.

17. Oosterhuis NM, Neubauer P, Junne S. Single-use bioreactors for microbial cultivation. Pharm. Bioprocess. 2013;1:167-77.

18. Eibl R, Löffelholz C, Eibl D. Single-use bioreactors-an overview. Single-use technology in biopharmaceutical manufacture. Hoboken: Wiley; 2011. p. 33-51.

19. Klöckner W, Diederichs S, Büchs J. Orbitally shaken single-use bioreactors. New York: Springer; 2013. p. 45-60. 
20. Eibl R, Kaiser S, Lombriser R, Eibl D. Disposable bioreactors: the current stateof-the-art and recommended applications in biotechnology. Appl Microbiol Biotechnol. 2010;86:41-9.

21. Neubauer P, Cruz N, Glauche F, Junne S, Knepper A, Raven M. Consistent development of bioprocesses from microliter cultures to the industrial scale. Eng Life Sci. 2013;13:224-38.

22. Hillig F, Pilarek M, Junne $S$, Neubauer P. Cultivation of marine microorganism in single-use systems. Adv Biochem Eng Biotechnol. 2014;138:179-206.

23. Singh V. Disposable bioreactor for cell culture using wave-induced agitation. Cytotechnology. 1999;30:149-58.

24. Lehmann N, Rischer H, Eibl D, Eibl R. Wave-mixed and orbitally shaken single-use photobioreactors for diatom algae propagation. Chem Ing Tech. 2013;85:197-201.

25. Eibl R, Werner S, Eibl D. Bag bioreactor based on wave-induced motion: characteristics and applications. Berlin: Springer; 2010. p. 55-87.

26. Jonczyk P, Takenberg M, Hartwig S, Beutel S, Berger RG, Scheper T. Cultivation of shear stress sensitive microorganisms in disposable bag reactor systems. J Biotechnol. 2013;167:370-6.

27. Junne S, Neubauer P. How scalable and suitable are single-use bioreactors? Curr Opin Biotechnol. 2018:53:240-7.

28. Casas López JL, Sánchez Pérez JA, Fernández Sevilla JM, Rodríguez Porcel EM, Chisti Y. Pellet morphology, culture rheology and lovastatin production in cultures of Aspergillus terreus. J Biotechnol. 2005;116:61-77.

29. Kim JH, Lebeault JM, Reuss M. Comparative study on rheological properties of mycelial broth in filamentous and pelleted forms. Eur J Appl Microbiol Biotechnol. 1983;18:11-6.

30. Gibbs PA, Seviour RJ, Schmid F. Growth of filamentous fungi in submerged culture: problems and possible solutions. Crit Rev Biotechnol. 2000;20:17-48.

31. Kaup B-A, Ehrich K, Pescheck M, Schrader J. Microparticle-enhanced cultivation of filamentous microorganisms: increased chloroperoxidase formation by Caldariomyces fumago as an example. Biotechnol Bioeng. 2008;99:491-8.

32. Driouch $H$, Hänsch R, Wucherpfennig T, Krull R, Wittmann C. Improved enzyme production by bio-pellets of Aspergillus niger: targeted morphology engineering using titanate microparticles. Biotechnol Bioeng. 2012;109:462-71.

33. Papagianni M, Mattey M. Morphological development of Aspergillus niger in submerged citric acid fermentation as a function of the spore inoculum level. Application of neural network and cluster analysis for characterization of mycelial morphology. Microb Cell Fact. 2006;5:3.

34. Wucherpfennig T, Lakowitz A, Krull R. Comprehension of viscous morphology — evaluation of fractal and conventional parameters for rheological characterization of Aspergillus niger culture broth. J Biotechnol. 2013;163:124-32.

35. Jüsten P, Paul GC, Nienow AW, Thomas CR. Dependence of mycelial morphology on impeller type and agitation intensity. Biotechnol Bioeng. 1996;52:672-84.

36. Wongwicharn A, McNeil B, Harvey LM. Effect of oxygen enrichment on morphology, growth, and heterologous protein production in chemostat cultures of Aspergillus niger B1-D. Biotechnol Bioeng. 1999;65:416-24.

37. Das RK, Brar SK. Enhanced fumaric acid production from brewery wastewater and insight into the morphology of Rhizopus oryzae 1526. Appl Biochem Biotechnol. 2014:172:2974-88.

38. Krijgsheld P, Bleichrodt R, van Veluw GJ, Wang F, Müller WH, Dijksterhuis J, et al. Development in Aspergillus. Stud Mycol. 2013;74:1-29.

39. Amanullah A, Christensen LH, Hansen K, Nienow AW, Thomas CR. Dependence of morphology on agitation intensity in fed-batch cultures of Aspergillus oryzae and its implications for recombinant protein production. Biotechnol Bioeng. 2002;77:815-26.

40. Wucherpfennig T, Kiep KA, Driouch H, Wittmann C, Krull R. Morphology and rheology in filamentous cultivations. Adv Appl Microbiol. 2010;72:89-136.

41. Wucherpfennig T, Hestler T, Krull R. Morphology engineering-osmolality and its effect on Aspergillus niger morphology and productivity. Microb Cell Fact. 2010:10:58

42. Driouch H, Sommer B, Wittmann C. Morphology engineering of Aspergillus niger for improved enzyme production. Biotechnol Bioeng. 2010;105:1058-68.
43. Driouch $\mathrm{H}$, Roth A, Dersch P, Wittmann C. Filamentous fungi in good shape: microparticles for tailor-made fungal morphology and enhanced enzyme production. Bioeng Bugs. 2011;2:100-4.

44. Sitanggang AB, Wu H-S, Wang SS, Ho Y-C. Effect of pellet size and stimulating factor on the glucosamine production using Aspergillus sp. BCRC 31742 Bioresour Technol. 2010;101:3595-601.

45. Choy V, Patel N, Thibault J. Application of image analysis in the fungal fermentation of Trichoderma reesei RUT-C30. Biotechnol Prog. 2011;27:1544-53.

46. Tepwong P, Giri A, Ohshima T. Effect of mycelial morphology on ergothioneine production during liquid fermentation of Lentinula edodes. Mycoscience. 2012;53:102-12

47. Amanullah A, Blair R, Nienow AW, Thomas CR. Effects of agitation intensity on mycelial morphology and protein production in chemostat cultures of recombinant Aspergillus oryzae. Biotechnol Bioeng. 1999;62:434-46.

48. Clark DS, Ito K, Horitsu H. Effect of manganese and other heavy metals on submerged citric acid fermentation of molasses. Biotechnol Bioeng. 1966;8:465-71.

49. Schügerl $K$, Wittler $R$, Lorenz T. The use of molds in pellet form. Trends Biotechnol. 1983;1:120-3.

50. Papagianni M. Fungal morphology and metabolite production in submerged mycelial processes. Biotechnol Adv. 2004;22:189-259.

51. Pirt SJ, Callow DS. Continuous-flow culture of the filamentous mould Penicillium chrysogenum and the control of its morphology. Nature. 1959;184:307-10.

52. Rocha-Valadez JA, Galindo E, Serrano-Carreón L. The influence of circulation frequency on fungal morphology: a case study considering Kolmogorov microscale in constant specific energy dissipation rate cultures of Trichoderma harzianum. J Biotechnol. 2007;130:394-401.

53. Braun S, Vecht-Lifshitz SE. Mycelial morphology and metabolite production. Trends Biotechnol. 1991;9:63-8.

54. Metz B, Kossen NWF. The growth of molds in the form of pellets-a literature review. Biotechnol Bioeng. 1977;19:781-99.

55. Elmayergi $\mathrm{H}$, Scharer $\mathrm{JM}$, Moo-Young M. Effects of polymer additives on fermentation parameters in a culture of $A$. niger. Biotechnol Bioeng. 1973;15:845-59.

56. Ruohang W, Webb C. Effect of cell concentration on the rheology of glucoamylase fermentation broth. Biotechnol Tech. 1995;9:55-8.

57. Jørgensen TR, Goosen T, van den Hondel CA, Ram AF, Iversen JJ. Transcriptomic comparison of Aspergillus niger growing on two different sugars reveals coordinated regulation of the secretory pathway. BMC Genomics. 2009; 10:44

58. Nitsche BM, Jørgensen TR, Akeroyd M, Meyer V, Ram AF. The carbon starvation response of Aspergillus niger during submerged cultivation: insights from the transcriptome and secretome. BMC Genomics. 2012;13:380.

59. Hillig F. Impact of cultivation conditions and bioreactor design on docosahexaenoic acid production by a heterotrophic marine microalga. Technische Universität Berlin, Faculty III-Process Sciences; 2014.

60. Hillig F, Annemüller S, Chmielewska M, Pilarek M, Junne S, Neubauer P. Bioprocess development in single-use systems for heterotrophic marine microalgae. Chem Ing Tech. 2013;85:153-61.

61. Wang X, Kang Y, Luo C, Zhao T, Liu L, Jiang X, et al. Heteroresistance at the single-cell level: adapting to antibiotic stress through a population-based strategy and growth-controlled interphenotypic coordination. MBio. 2014;5:e00942.

62. Nikolic N, Schreiber F, Dal Co A, Kiviet DJ, Bergmiller T, Littmann S, et al. Cellto-cell variation and specialization in sugar metabolism in clonal bacterial populations. PLoS Genet. 2017;13:e1007122.

63. Martins BM, Locke JC. Microbial individuality: how single-cell heterogeneity enables population level strategies. Curr Opin Microbiol. 2015;24:104-12.

64. Jørgensen TR, Nitsche BM, Lamers GE, Arentshorst M, Van Den Hondel CA, Ram AF. Transcriptomic insights into the physiology of Aspergillus niger approaching a specific growth rate of zero. Appl Environ Microbiol. 2010;76:5344-55.

65. Lemoine A, Maya Martínez-Iturralde N, Spann R, Neubauer P, Junne S. Response of Corynebacterium glutamicum exposed to oscillating cultivation conditions in a two- and a novel three-compartment scale-down bioreactor. Biotechnol Bioeng. 2015;112:1220-31. 